\title{
Study on Separation and Enrichment of Trace Cobalt(II) using Microcrystalline Phenolphthalein Adsorption System
}

\author{
Xinrong Wen ${ }^{1, a}$ and Yujun Zhong $2, b$ \\ ${ }^{1}$ College of Chemistry and Environment, Jiaying University , Meizhou , Guangdong 514015, China \\ ${ }^{2}$ College of Chemistry and Environment,Jiaying University,Meizhou, Guangdong 514015, China \\ awxrong5093@hotmail.com, ’mzzyjj@163.com
}

\section{Keywords:cobalt, separation/enrichment , microcrystalline phenolphthalein,adsorption}

Abstract: A new method of using adsorption microcrystalline phenolphthalein adsorption to separate and enrich trace cobalt has been developed. The effects of different parameters, such as the dosages of 1-(2-pyridylazo)-2-naphthol(PAN), phenolphthalein and various salts on the enrichment yield of $\mathrm{Co}^{2+}$ have been investigated. The possible enrichment mechanism of $\mathrm{Co}^{2+}$ was discussed. The results showed that under the optimum conditions, $\mathrm{Co}^{2+}$ could be quantificationally adsorbed on the surface of microcrystalline phenolphthalein in the form of the chelate precipitate of $\mathrm{Co}(\mathrm{II})-\mathrm{PAN}$, while $\mathrm{Mn}^{2+}, \mathrm{Zn}^{2+}$ and $\mathrm{Al}^{3+}$ could not be adsorbed at all. Therefore, $\mathrm{Co}^{2+}$ was completely separated from the above metal ions. A new method for separation/enrichment of trace cobalt using microcrystalline phenolphthalein adsorption system was established. The proposed method has been successfully applied to the separation of $\mathrm{Co}^{2+}$ in the synthetic water samles, and the enrichment yield was $94.3 \% \sim 102.2 \%$.

\section{Introduction}

Cobalt is one of the essential microelements for humans, animals and plants. The deficiency of cobalt in human and animals results in retarding growth rate,anaemia and so on, while excess intake of cobalt leads to toxic effects, such as vasodilatation,flushing and cardiomyopathy. Therefore, it is of great importance and significance for life science to separate and determinate trace cobalt in environmental samples. Since the content of $\mathrm{Co}^{2+}$ in environment is usually very low, separation and enrichment must be carried out before measurement.

There are many methods to separate and enrich Co(II), such as solvent extraction, ${ }^{1-2}$ liquid-liquid extraction, ${ }^{3}$ solid phase extraction, ${ }^{4-5}$ cloud point extraction, ${ }^{6-7}$ ion exchange separation, ${ }^{8}$ flotation separation, ${ }^{9}$ column chromatography ${ }^{10}$ HPLC,${ }^{11}$ reversed-phase HPLC, ${ }^{12}$ The techniques for the separation enrichment of cobalt using microcrystalline naphthalene adsorption system have been reported ${ }^{13-14}$. Although the results are very satisfactory, this method have some limitations. Naphthalene is easy to sublimate into air, which will seriously pollute environment and affect the health of experimental operators.This problem limit the practical application of this method. Using microcrystalline phenolphthalein modified with PAN as solid phase extractant to separate and enrich Co(II) has not been reported in any literature.

In this paper we have studied the separation/enrichment of $\mathrm{Co}^{2+}$ using microcrystalline phenolphthalein modified with PAN. In the presence of $0.50 \mathrm{~g} \mathrm{NaCl}$, when the dosage of $0.001 \mathrm{~mol} / \mathrm{L}$ PAN solution was $3.00 \mathrm{~mL}$ and $0.05 \%$ phenolphthalein solution was $0.20 \mathrm{~mL}$, respectively, $\mathrm{Co}^{2+}$ can be quantificationally adsorbed on the surface of microcrystalline phenolphthalein in the form of the chelate precipitate of $\mathrm{Co}(\mathrm{II})-\mathrm{PAN}$, while $\mathrm{Mn}^{2+}, \mathrm{Zn}^{2+}$ and $\mathrm{Al}^{3+}$ can not be adsorbed at all. Therefore, the quantitative separation/ enrichment of $\mathrm{Co}^{2+}$ from these metal ions can be achieved without any masking agent. A new method for separation/enrichment of trace cobalt using microcrystalline phenolphthalein adsorption system was 
established,and it has been successfully applied to the separation of $\mathrm{Co}^{2+}$ in the synthetic water samles with satisfactory results.

Compared this proposed method with literatures, ${ }^{13-14}$ environmental pollution caused by sublimation of naphthalene or organic reagent can be eliminated, and the harm to operators in experiment can be avoided. This method has characteristics such as simply,rapidness, convenience,economy and so on.

\section{Experimental}

\section{Equipment and reagents}

A model 723S spectrophotometer (Shanghai No.3 Analysis Equipment Plant) was used for photometric measurements. A model UV-2401 UV-visible spectrophotometer(The Shimadzu Corporation, japan) was used for scanning the absorption spectrum.

1-(2-pyridylazo)-2-naphthol(PAN) ethanol solution: $0.001 \mathrm{~mol} \cdot \mathrm{L}^{-1}$. Phenolphthalein(PP) ethanol solution:0.05\%. Borax solution: $0.1 \mathrm{~mol} \cdot \mathrm{L}^{-1} \cdot 1.0 \times 10^{-3} \mathrm{~mol} \cdot \mathrm{L}^{-1}$ of 4 -(2-pyridylazo) resorcinol (PAR) ethanol solution was prepared by dissolving $0.1076 \mathrm{~g}$ PAR in $500 \mathrm{~mL}$ of ethanol. A stock of standard solution of $\mathrm{Co}^{2+}: 1.000 \mathrm{~g} \cdot \mathrm{L}^{-1}$.A working standard solution was prepared by appropriately diluting the stock standard solution.Standard solution of other metal ions was prepared according to reference 15a, and buffer solutions of different $\mathrm{pH}$ was prepared as reference $15 \mathrm{~b}$.

All reagents were of analytical reagent grade.Bidistilled water was used throughout.

\section{Methods}

$50 \mu \mathrm{g}$ of $\mathrm{Co}^{2+}$,a given amounts of $0.001 \mathrm{~mol} \cdot \mathrm{L}^{-1} \mathrm{PAN}$ ethanol solution and $0.05 \%$ phenolphthalein ethanol solution were added into a $25 \mathrm{~mL}$ ground color comparison tube. Then diluted the mixture to $10.00 \mathrm{~mL}$ with bidistilled water. $0.50 \mathrm{~g} \mathrm{NaCl}$ was added, shaken adequately and they were kept still for a moment.1.00 mL of filtrate was transferred into another $25 \mathrm{~mL}$ ground color comparison tube, then 1.5 $\mathrm{mL}$ PAR ethanol solution and $3.0 \mathrm{~mL}$ borax solution were added. The solution was diluted to the mark and the absorbance was measured at $510 \mathrm{~nm}$ against the reagent blank prepared in the same way. The amount of $\mathrm{Co}^{2+}$ remained in the solution was calculated. The enrichment yield of $\mathrm{Co}^{2+}(\mathrm{E} / \%)$ was calculated according to the determination results. Photometric analysis of other metal ions was referring the reference 16.

The determination of the content of trace $\mathrm{Co}^{2+}$ in microcrystalline phenolphthalein adsorption solid phase is as follow: the precipitation obtained by filtration was dissolved in ethanol, and then was transferred into a $25 \mathrm{~mL}$ ground color comparison tube and diluted the mixture to $10.00 \mathrm{~mL}$ with bidistilled water, shaken adequately and they were kept still for a moment, and the content of $\mathrm{Co}^{2+} \mathrm{was}^{2}$ determined in the same method above.

\section{Results and discussion}

\section{Effect of phenolphthalein}

In order to investigate the effect of phenolphthalein dosage on the enrichment yield of $\mathrm{Co}^{2+}, 50 \mu \mathrm{g}$ of $\mathrm{Co}^{2+}, 3.00 \mathrm{~mL}$ of PAN ethanol solution were applied to the proposed method.The results show that the enrichment yield of $\mathrm{Co}^{2+}$ is $80.2 \%$ in the absence of phenolphthalein.It is probable that $\mathrm{Co}^{2+}$ can directly react with PAN to form the chelate precipitate of Co-PAN. It is consistent with the phenomenon of precipitate which can be directly observed without phenolphthalein in experiment.

The enrichment yield of $\mathrm{Co}^{2+}$ increase with the increase of phenolphthalein dosage.The enrichment yield of $\mathrm{Co}^{2+}$ is $100 \%$ when the dosage of phenolphthalein is $0.10 \mathrm{~mL}$ or more. It is probable that PAN 
adsorbed onto microcrystalline phenolphthalein(MPP) has higher concentration and can react with $\mathrm{Co}^{2+}$ left in the solution to form the chelate precipitate of Co-PAN, and the chelate precipitate of Co-PAN can be adsorbed on the surface of microcrystalline PP. This indicates that microcrystalline phenolphthalein modified with PAN can perfectly adsorb trace $\mathrm{Co}^{2+}$ in solution, and the concentration of $\mathrm{Co}^{2+}$ decrease to zero. Therefore, $0.20 \mathrm{~mL}$ of phenolphthalein ethanol solution was selected.

\section{Effect of PAN}

The effect of PAN dosage on the enrichment yield of $\mathrm{Co}^{2+}$ was shown in Fig. 1.The results show that the enrichment yield of $\mathrm{Co}^{2+}$ is zerc without PAN in the solution, or $\mathrm{Co}^{2+}$ is totally left in the solution. It is likely that $\mathrm{Co}^{2+}$ cannor directly adsorbed on the surface of microcrystalline PP when the solution withoul PAN.With the increase of PAN dosage, the enrichment yield of $\mathrm{Co}^{2+}$ increase. For the reason that $\mathrm{Co}^{2+}$ can react with PAN to form the water-insoluble chelate of Co-PAN, and the chelate precipitate of Co-PAN can be adsorbed the surface of microcrystalline PP.The amount of

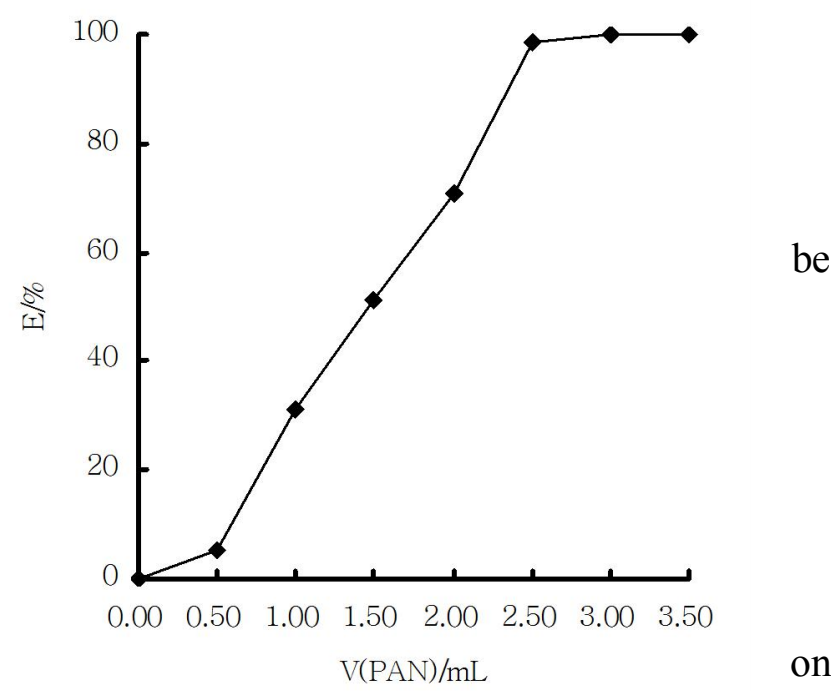
Co-PAN increases when the solution

Fig. 1. Effect of PAN dosage on the enrichment includes more PAN. It leads to the increase of enrichment yield of $\mathrm{Co}^{2+}$. When the dosage of PAN was $3.00 \mathrm{~mL}, \mathrm{Co}^{2+}$ can be completely

$$
\begin{aligned}
& \text { yield of } \mathrm{Co}^{2+} \\
& \mathrm{Co}^{2+}: 50 \mu \mathrm{g} \text {; phenolphthalein }(0.05 \%): 0.20 \mathrm{~mL} \text {; } \\
& \text { PAN: } 0.001 \mathrm{~mol} \cdot \mathrm{L}^{-1}
\end{aligned}
$$

retained on the surface of microcrystalline PP. The enrichment yield of $\mathrm{Co}^{2+}$ maintained $100 \%$ with further increasing the the dosage of PAN. Hence,3.00 $\mathrm{mL}$ of PAN ethanol solution was chosen for all further studies.

\section{Enrichment mechanism of $\mathrm{Co}^{2+}$}

Based on the results above, it can be concluded that $\mathrm{Co}^{2+}$ can not be enriched when the solution includes phenolphthalein but not PAN, and $\mathrm{Co}^{2+}$ can not be completely enriched when the solution includes PAN but not phenolphthalein. Only in the simultaneous presence of PAN and phenolphthalein in the solution, can $\mathrm{Co}^{2+}$ be completely enriched. Therefore, when $\mathrm{Co}^{2+}$, PAN and phenolphthalein simultaneous existed in the solution, it seems reasonable that the enrichment mechanism of $\mathrm{Co}^{2+}$ is as follows:

(1) When the solution includes PAN but not phenolphthalein, $\mathrm{Co}^{2+}$ can directly react with PAN to form the chelate precipitate of Co-PAN, which leads to the decrease of the concentration of $\mathrm{Co}^{2+}$ in the solution.

$$
\mathrm{Co}^{2+}+\mathrm{PAN} \rightarrow \mathrm{Co}-\mathrm{PAN} \downarrow
$$

(2) When the solution includes both PAN and phenolphthalein, the chelate precipitate of Co-PAN in water phase was adsorbed on the surface of microcrystalline PP, meanwhile PAN adsorbed onto microcrystalline PP reacts with $\mathrm{Co}^{2+}$ left in the solution to form the chelate precipitate of Co-PAN, and the chelate precipitate of Co-PAN can be adsorbed on the surface of microcrystalline PP(MPP). 


$$
\begin{aligned}
& \mathrm{Co}-\mathrm{PAN} \downarrow \quad \rightarrow \quad \mathrm{Co}-\mathrm{PAN} \downarrow \\
& \text { (Water phase) (MPP phase) } \\
& \mathrm{Co}^{2+}+\mathrm{PAN} \rightarrow \mathrm{Co}-\mathrm{PAN} \downarrow \\
& \text { (Water phase) (MPP phase) (MPP phase) }
\end{aligned}
$$

\section{Effects of various salts}

When the dosage of $\mathrm{Co}^{2+}, 0.05 \%$ PP solution and $0.001 \mathrm{~mol} \cdot \mathrm{L}^{-1} \mathrm{PAN}$ solution were $50 \mu \mathrm{g}, 0.20 \mathrm{~mL}, 3.00$ $\mathrm{mL}$ respectively, the effects of various salts including $\mathrm{NaCl}, \mathrm{NaNO}_{3},\left(\mathrm{NH}_{4}\right)_{2} \mathrm{SO}_{4}$ and $\mathrm{KBr}$ on the enrichment yield of $\mathrm{Co}^{2+}$ were investigated. The results showed that the existence of $\mathrm{NaCl}, \mathrm{NaNO}_{3}$, $\left(\mathrm{NH}_{4}\right)_{2} \mathrm{SO}_{4}, \mathrm{KBr}$ did not decrease the enrichment yield of $\mathrm{Co}^{2+}$, and liquid-solid divarication could be realized in the presence of $\mathrm{NaCl}, \mathrm{NaNO}_{3}$ and $\mathrm{KBr}$ respectively.The presence of $\mathrm{NaCl}$ speeded up liquid-solid divarication and made the interface more clear between two phases, and consequently $\mathrm{Co}^{2+}$ could be separated quickly and completely. When $0.50 \mathrm{~g} \mathrm{NaCl}$ was added, it could make liquid-solid phase separation perfectly. Therefore, $0.50 \mathrm{~g} \mathrm{NaCl}$ was chosen.

\section{The enrichment yield of different metal ions}

When $\mathrm{Co}^{2+}$ dosage was $50 \mu \mathrm{g}$, the dosage of PAN and PP solution was $3.00 \mathrm{mLand} 0.2 \mathrm{~mL}$ respectively, the enrichment yield of $\mathrm{Co}^{2+}$ was $100 \%$. Under the same conditions, $\mathrm{Mn}^{2+}, \mathrm{Zn}^{2+}$ can not be enriched at all and the enrichment yield of $\mathrm{Al}^{3+}$ was 5.3\%. Therefore, $\mathrm{Co}^{2+}$ can be separated from $\mathrm{Mn}^{2+}, \mathrm{Zn}^{2+}$ and $\mathrm{Al}^{3+}$.

\section{Separation experiments}

Under the chosen conditions, the separations of $\mathrm{Co}^{2+}$ from $\mathrm{Mn}^{2+}, \mathrm{Zn}^{2+}$ and $\mathrm{Al}^{3+}$ in synthesized samples of binary and polybasic system were studied respectively. The results are shown in Table 1 and Table 2.

Table 1. The separation results of binary-mixed ions

\begin{tabular}{ccccccc}
\hline Mixed ions & \multicolumn{2}{c}{ Dosage of metal ions $(\mu \mathrm{g})$} & \multicolumn{2}{c}{ Content of metal ions in water phase $(\mu \mathrm{g})$} & \multicolumn{2}{c}{ Enrichment yield(E/\%) } \\
& $\mathrm{Co}$ & $\mathrm{Me}$ & $\mathrm{Co}$ & $\mathrm{Me}$ & $\mathrm{Co}$ & $\mathrm{Me}$ \\
\hline $\mathrm{Co}^{2+}-\mathrm{Mn}^{2+}$ & 50 & 200 & 0.2 & 208.3 & 99.6 & -4.2 \\
& 50 & 300 & 0.1 & 314.0 & 99.8 & -4.7 \\
& 50 & 500 & 0.1 & 534.5 & 99.8 & -6.9 \\
$\mathrm{Co}^{2+}-\mathrm{Zn}^{2+}$ & 50 & 50 & 0.2 & 54.0 & 99.6 & -8.0 \\
& 50 & 100 & 0.0 & 102.4 & 100 & -2.4 \\
& 50 & 150 & 0.1 & 153.5 & 99.8 & -2.3 \\
$\mathrm{Co}^{2+}-\mathrm{Al}^{3+}$ & 50 & 50 & 0.3 & 49.3 & 99.4 & 1.4 \\
& 50 & 100 & 0.0 & 97.8 & 100 & 2.2 \\
& 50 & 150 & 0.2 & 149.4 & 99.6 & 0.4 \\
\hline
\end{tabular}

Me represents other metal ions except $\mathrm{Co}^{2+}$.

Table 2. Separation and determination results of $\mathrm{Co}^{2+}$ from polybasic-mixed ions

\begin{tabular}{lccc}
\hline Number of the synthesized samples & 1 & 2 & 3 \\
\hline Dosage of $\mathrm{Co}^{2+}(\mu \mathrm{g})$ & 50.0 & 100.0 & 200.0 \\
Dosage of $\mathrm{Me}(\mu \mathrm{g})$ & 100.0 & 200.0 & 300.0 \\
$\mathrm{Co}^{2+}$ found in solid phase $(\mu \mathrm{g})$ & 49.2 & 94.3 & 204.3 \\
Enrichment yield of $\mathrm{Co}^{2+}(\mathrm{E} / \%)$ & 98.4 & 94.3 & 102.2 \\
\hline
\end{tabular}

Me represents $\mathrm{Mn}^{2+}, \mathrm{Zn}^{2+}$ and $\mathrm{Al}^{3+}$. 


\section{Conclusion}

In this paper, a new method for the separation/enrichment of trace $\mathrm{Co}^{2+}$ using microcrystalline phenolphthalein adsorption system was reported. The proposed method has been successfully used for the separation of trace $\mathrm{Co}^{2+}$ in the synthetic water samles with satisfactory results. It is obvious that this study has certain practical significance and foreground of application on establishing a new method of separation/enrichment of teace cobalt( II ).

\section{Acknowledgement}

This work was financially supported by scientific research project of Jiaying University (2016KJY08).

\section{References}

[1] Zuha,S.;Rusheed,A. J.Radioanal.Nucl.Chem.1989,133(2), p. 241.

[2] Izquierdo,A.; Compano,R.; Bars,E. Mikrochim Acta.1984,II, p. 343.

[3] Mitra,B.-K.; Pal,B.-K.; Chowdhury,R.-P. Mikrochim Acta.1982, II, p.257.

[4] Muharrem,I.;Gokce,K.;Mehmet,Y Environ. Chem. Lett. 2010,8, p. 283.

[5] Yang,G.-Y.; Dong,X.-C.;Hu,Q.-F.;Yin,J.-Y. Anal.Lett.2002, 35(10), p. 1735.

[6] Safavi,A.; Abdollahi,H.; Nezhad,M.-R.-H.; Kamali,R.Spectrochim.Acta,Part A.2004, 60(12), p. 2897.

[7] Farzaneh,S.;Nader,S. Anal.Chim.Acta.2006,577(2), p. 238.

[8] Marino,D.-F.; Ingle Jr,J.-D. Anal. Chem. 1981, 53 (2), p. 292.

[9] Čundeva,K.; Stafilov,T.; Pavlovska,G. Microchem. J. 2000,65(2), p. 165.

[10] Sharma,R.-K.Analyst, 1995,120, p. 2203.

[11] Khuhawar,M.-Y.; Lanjwani,S.-N. J.Chromatogr., A.1995,695(1), p. 132.

[12] Niwa,H.; Yasui,T.; Ishizuki,T.; Yuchi,A.; Yamada,H.; Wada,H. Talanta.1997, 45(2), p. 349.

[13] Gholivand,M.-B.; Mozaffari,Y.; Sobhani,Sh.; Ghasemi,J. J.Anal.Chem. 2008, 63(3), p. 232.

[14] Lin,J.-L.J.Chin.Chem.Soc.1984, 31, p. 395.

[15] Chang,W.-B.:Li,K.-A. Brief Handbook of Analytical Chemistry;Beijing University Press:Beijing, 1981;a p. 240,b p. 262. (in Chinese)

[16] Pan,J.-M.; Chen,Y.-S.; Yan,H.-T. Chromogenic Agent and Its Application in Metallurgical Analysis; Shanghai Scientific and Technical Publisher :Shanghai, 1981; p. 116. (in Chinese) 